\title{
Assessment of Quality of Life in Adults Living at Charity Homes in Saudi Arabia
}

\author{
Samia S. Abdulmageed ${ }^{1} \&$ Ikhlas O. Saeed ${ }^{2}$ \\ ${ }^{1}$ Alneelain University, Graduate College, Khartoum, Sudan \\ ${ }^{2}$ King Abdulaziz University, Faculty of Applied Medical Sciences, Jeddah, Saudi Arabia \\ Correspondence: Samia S. Abdulmageed, Alneelain University, Graduate College, Khartoum, Sudan.
}

Received: March 1, 2017 Accepted: June 12, 2017 Online Published: June 16, 2017

doi:10.5539/gjhs.v9n9p19 URL: https://doi.org/10.5539/gjhs.v9n9p19

\begin{abstract}
There is a rising interest in the Quality of Life (QoL) research in the Arabian countries. The study aimed to analyze the association between the health satisfaction, environment, age, and the physical functions to determine the quality of life among adults living in charity homes in Jeddah, Saudi Arabia. The participants recruited for the study were adults, living in charity homes in Jeddah to analyze the results through a quantitative research design. The sample size included in the study was 136, which included the participants from different charity homes in Jeddah. SF-36 was appropriately used to examine the health status of the participants. WHOQOL-BRIEF questionnaire was used for the collection of primary data at the time of interviews. The statistically significant results have been evaluated through the independent t-test between the groups, based on the characteristics of the participants for average SF-36 domain scores. However, ANOVA test evaluated insignificant results on the basis of educational level as the $p$-value obtained is greater than the level of significance $(0.850>0.05)$. Positive responses for all four domains of SF-36 instrument have been obtained, which recommended that further improvements in the charity homes is required to provide the awareness regarding the security and medication facilities.
\end{abstract}

Keywords: quality of life, homeless, charity homes, influencing factors, health care settings

\section{Introduction}

The important goal for nursing services and health professions in general in healthcare sector is to assist people in improving their quality of life $(\mathrm{QoL})$. Therefore, it is important to determine the factors that influence QoL in the community. WHOQOL (World Health Organization Quality of Life Assessment Group) has defined QoL as individuals' perception of their position in life, regarding culture and value systems (WHOQOL, 1995). There is a considerable increase in the number of adult and elderly people across the world. The increase has been recorded at almost 300\% in the older population of developed countries as well as developing countries (Aydin et al., 2015). It has brought the attention of healthcare professionals and policy makers towards long-term healthcare services and other associated issues. Elderly people are limited in their capability to live independently. They often face frailty issues, limited mobility, problems related to mental health, and physical health problems. There is a lack of literature on the information related to the prevalence of homeless population. The phenomenon of homelessness is associated with different risk behaviors. These aspects may include substance abuse, crime, exploitation, and even death. Ha et al. (2015) asserted that people get engaged in these behaviors because they are forced to do so for their survival (Ha et al., 2015).

In Saudi Arabia, Ministry of Social Affairs is in the process of reviewing the way shelter/charity homes are administered. The ministry also aims to shift their locations in South Jeddah (Saudi Gazette, 2015). It has always been a debatable issue in the local context. The studies must emphasize on several considerations that include improvement of work environment, privacy standards, and provision of services (Veenema et al., 2015). There is a need to demonstrate the issues related to security and safety measures in the charity homes.

The main purpose of this study was to investigate the relationship between physical function, health satisfaction, age, and environment that may determine the QoL of adult in charity home of Jeddah. The study analyzed quality of life among homeless adult people in the charity home in Jeddah. The outcome variable included four domains of the SF-36 instrument. WHOQOL-BRIEF questionnaire was used for the collection of primary data from the 
patients at the charity home in Jeddah. The study found positive responses for all four domains of SF-36 instrument. The findings revealed the importance of health education programs by focusing on approaches related to family bonding. It would result in positive outcomes for vulnerable population.

\section{Methods}

2.1 Study Design

The study has adopted quantitative cross-sectional study design to assess the quality of life in adults living at charity homes in Saudi Arabia. The design was selected, based on a structured QoL questionnaire in a representative sample from the charity home. The study has been conducted, recruiting the residents of charity home in Jeddah, Saudi Arabia. The study has recruited adults, living in different charity homes in Jeddah to assess their quality of life. The mean score of QoL was estimated at $5 \%$ of type I error and a standard deviation of $8 \mathrm{QoL}$ scores of the studied population. Using a precision of one QoL score of either side, the study has selected 136 participants for retrieving outcomes generously.

\subsection{Data Collection Tools}

The WHOQOL was used in this study, which evaluated the quality of life and described the development of WHOQOL-BREF, which is an abbreviated version of the WHOQOL-100. This instrument has many uses, including use in medical practice, research, audit, and in policy making. The researcher adopted the Arabic version to suit the culture and religion of the population under the study. Data was analyzed using SPSS (Statistical Package for the Social Sciences). The participants were interviewed on the basis of WHOQOL questionnaire and SF-36, which assisted to evaluate the health status and quality of life among every individual. The targeted population was the adults, living in charity homes in Jeddah, Saudi Arabia. All 136 adults were interviewed to have information collected effectively for further analysis. SF-36 or WHOQOL questionnaire was used as data collection instrument for proper reliability and validity of the data obtained.

\subsection{Ethical Consideration}

An approval from the charity home administration office was obtained. A verbal consent was taken from participants before interviewing. The collected data was treated confidentially.

\subsection{Statistical Analysis}

This study was conducted using the SF-36 QoL tool that provided the health status of adults living in charity homes. There are different reasons, why WHO developed a quality of life assessment. It helps to measure health status and also beyond health indicators, which included mortality and morbidity (World Health Organization., 2014). The validity and reliability of WHOQOL-BRIEF in Arabic version of QoL has also been evaluated to provide the validity of the instrument used for assessment of QoL among the patients at charity homes. Cronbach's alpha was used to estimate the reliability of the SF-36. The collected data was then analyzed through SPSS (Statistical Package of Social Sciences). Descriptive table has been generated, which represented mean and standard deviation of the responses. Independent samples test and ANOVA test have been applied to make comparison between the mean and analysis of variance along with its significance respectively. Independent t-test and ANOVA tests were used to examine the association between participants' characteristics and average SF-36 domain scores. Pearson's correlation coefficient was used to examine the correlation between the domains of SF-36.

\section{Results}

\subsection{Strength of Association}

Pearson's correlation coefficient value was greater than 0.40 that highlighted the level of agreement between domains of SF-36. Correlations $>0.4$ were considered acceptable. The responses of the questions were transformed into domain scores, and the correlation was determined between the domain scores of participants. A positive correlation was found between the domain scores of the participants. It implies that the participants that responded in the positive direction for physical domain also responded positively for psychological, social, and environmental domain.

\subsection{Comparing the Means}

In the study, descriptive analysis was performed, which has evaluated the percentages, frequencies, ranges, means, and standard deviations (SD). The results of independent t-test and ANOVA tests showed statistically significant differences between groups based on participants' characteristics for average SF-36 domain scores. For the independent $t$-test, participants were divided into two independent groups of male and female. The findings 
showed significant variations in the mean total scores of males and females. The standard level of significance considered for the study is $\alpha=0.05$. The $p$-values less than 0.05 shows significant association between the targeted variables.

The independent sample t-test in table 1 has shown significant mean differences ( $\mathrm{p}$-value $=0.001)$. ANOVA test in table 1 showed that the association between the variables is insignificant as the p-value is greater than the level of significance. $(0.850>0.05)$. The level of significance was not below .05 . Hence, statistically significant differences were not found in the mean total scores of participants based on education level. It ensures that domain variables are correlated with each other, and hypothesis is accepted.

Table 1. Independent samples test and ANOVA test

\begin{tabular}{|c|c|c|c|c|c|c|c|c|c|c|}
\hline & & \multicolumn{2}{|c|}{$\begin{array}{l}\text { Levene's Test for } \\
\text { Equality of } \\
\text { Variances }\end{array}$} & \multicolumn{7}{|c|}{ t-test for Equality of Means } \\
\hline & & \multirow[t]{2}{*}{$\mathrm{F}$} & \multirow[t]{2}{*}{ Sig. } & \multirow[t]{2}{*}{$\mathrm{t}$} & \multirow[t]{2}{*}{ Df } & \multirow[t]{2}{*}{$\begin{array}{l}\text { Sig. } \\
\text { (2-tailed) }\end{array}$} & \multirow[t]{2}{*}{$\begin{array}{l}\text { Mean } \\
\text { Difference }\end{array}$} & \multirow[t]{2}{*}{$\begin{array}{l}\text { Std. Error } \\
\text { Difference }\end{array}$} & \multicolumn{2}{|c|}{$\begin{array}{l}95 \% \text { Confidence } \\
\text { Interval of the } \\
\text { Difference }\end{array}$} \\
\hline & & & & & & & & & Lower & Upper \\
\hline \multirow[t]{2}{*}{$\begin{array}{l}\text { Total } \\
\text { Score }\end{array}$} & $\begin{array}{l}\text { Equal } \\
\text { variances } \\
\text { assumed }\end{array}$ & 7.033 & .009 & 3.536 & 121 & .001 & 8.00081 & 2.26260 & 3.52140 & 12.48023 \\
\hline & $\begin{array}{l}\text { Equal } \\
\text { variances } \\
\text { not } \\
\text { assumed }\end{array}$ & & & 8.597 & 47.104 & .000 & 8.00081 & .93062 & 6.12876 & 9.87286 \\
\hline \multicolumn{11}{|c|}{ ANOVA } \\
\hline & & \multicolumn{2}{|c|}{ Sum of Squares } & & Df & \multicolumn{2}{|c|}{ Mean Square } & $\mathrm{F}$ & \multicolumn{2}{|c|}{ Sig. } \\
\hline \multicolumn{2}{|c|}{ Between Groups } & \multicolumn{2}{|c|}{78.702} & & 19 & \multicolumn{2}{|c|}{19.675} & .340 & \multicolumn{2}{|c|}{.850} \\
\hline \multicolumn{2}{|c|}{ Within Groups } & \multicolumn{2}{|c|}{6761.823} & & 117 & \multicolumn{2}{|c|}{57.793} & & & \\
\hline \multicolumn{2}{|l|}{ Total } & \multicolumn{2}{|c|}{6840.525} & & \multicolumn{3}{|l|}{136} & & & \\
\hline
\end{tabular}

\footnotetext{
Along with statistical assurance, it is further plausible in general, since various studies and healthcare organizations positively claimed that physical activities and desirable environmental conditions, designed according to age, will result in highly satisfied health conditions. Further making significance level of ANOVA certain, Center for Disease Control and Prevention (CDC) suggested that various physical activities and healthy environment are necessary for people to improve their quality of life (CDC, 2015).

Significance level (0.850) in ANOVA table indicated that four determined domains of this study are strictly correlated. Each of them has their contribution in quality of life, specifically in charitable homes, where people are mostly unknown to each other. Together, these domains would have a positive synergy impact on quality of living, which is essential for each group.

This research study has utilized four different variables for conducting the research study. Four of the variables are seemed to be closely associated with the factor of quality of life. It has been evaluated from the findings that demographics of the participants played a major role in influencing quality of life during personal and professional life. The statistical approach has indicated that 136 participants participated in this study; out of which, 82 individuals were illiterate. From the statistical perspective, it has been evaluated that most of the illiterate individuals had poor extent of quality of life comparatively to the other classes. Individuals, having secondary or intermediate educational level, were also coping with the state of deprived quality of life. Therefore, the statistical interference has presented its outcomes that higher education or educational level has a direct impact on quality of life (Table 2).
} 
Table 2. Descriptive statistics

\begin{tabular}{|c|c|c|c|c|c|c|c|c|}
\hline & \multirow{2}{*}{$\mathrm{N}$} & \multirow{2}{*}{ Mean } & \multirow{2}{*}{$\begin{array}{l}\text { Std. } \\
\text { Deviation }\end{array}$} & \multirow{2}{*}{$\begin{array}{l}\text { Std. } \\
\text { Error }\end{array}$} & \multicolumn{2}{|c|}{$\begin{array}{l}95 \% \text { Confidence Interval } \\
\text { for Mean }\end{array}$} & \multirow{2}{*}{ Minimum } & \multirow{2}{*}{ Maximum } \\
\hline & & & & & $\begin{array}{l}\text { Lower } \\
\text { Bound }\end{array}$ & $\begin{array}{l}\text { Upper } \\
\text { Bound }\end{array}$ & & \\
\hline Intermediate & 29 & 94.11 & 8.334 & 1.634 & 90.74 & 97.48 & 78.0 & 105.0 \\
\hline Secondary & 8 & 96.25 & 3.105 & 1.097 & 93.65 & 98.84 & 94.0 & 100.0 \\
\hline Bachelor & 10 & 95.50 & 2.415 & .763 & 93.77 & 97.22 & 92.0 & 97.0 \\
\hline Masters & 5 & 94.50 & . & . & . & . & 103.0 & 103.0 \\
\hline $\mathrm{PhD}$ & 1 & 101.00 & . & . & . & . & 101.0 & 101.0 \\
\hline Illiterate & 82 & 95.46 & 8.033 & .915 & 93.64 & 97.29 & 80.0 & 114.0 \\
\hline Missing & 2 & -- & -- & -- & -- & -- & -- & -- \\
\hline Total & 136 & 95.27 & 7.518 & .680 & 93.93 & 96.62 & 78.0 & 114.0 \\
\hline
\end{tabular}

The second major factor, which has been identified in this study, was related to physical function. It has been evaluated by the statistical analysis that majority of the physically active individuals had appropriate level of quality of life. It has been further observed that physically fit individuals were able to perform their daily personal and professional tasks in an appropriate manner. Such participants had normal regulation of the body process, which in turn resulted in better performance. Therefore, it can be said that physical fitness is closely connected with better quality of life as reflected in table 3 .

The third major variable of the study is health satisfaction. It is a fact that the satisfaction level of the patients in regards of their health is directly associated with better recovery and quality of life. From the outcomes represented in Table 3, it has been observed that the individuals, having higher health satisfactory level, had enhanced level of quality of life. Comparatively, the participants, who were dissatisfied with their health, had deprived level of QOL. Therefore, it has been evaluated that health satisfaction had also similar impact on the quality of life.

Environmental domain is a vast area, which is necessary to be understood in regards of quality of life among general population. Three environmental factors have been identified by this research study as presented in table 3 , which mainly included pollution, crowd, and traffic. Three of these factors have been observed from the perspective of quality of life. It has been evaluated that environmental domain is closely connected while maintaining quality of life among general population. Table 3 has represented the environmental domain and quality of life among the adults living in charity homes. It can be observed that majority of the participants were satisfied with the quality of life provided in the charity homes of Jeddah, as only 80 participants showed their satisfaction concerning the environment and health. Whereas, 55 participants were discontented with the health and environmental status of the charity homes. Lower pollution, no crowd in daily routine, less traffic concerns could be the ways of improving quality of life among adults living in charity homes in Jeddah, Saudi Arabia. 
Table 3. Health satisfaction and Quality of Life; physical fitness and Quality of Life; environmental domain and Quality of Life

\begin{tabular}{llll}
\hline & $\mathrm{N}$ & Max Score & Min Score \\
\hline Satisfied & 80 & 101.00 & 101.00 \\
Dissatisfied & 55 & 74.25 & 75.45 \\
Total & 136 & 87.625 & 176.45 \\
Std. Deviation & Std. Error & Max & Min \\
7.33464 & 1.65456 & 95.00 & 105.00 \\
2.10530 & 1.11789 & 68.00 & 70.00 \\
6.51886 & .68073 & 81.50 & 87.50 \\
\hline & Pollution & Crowd & Traffic \\
\hline Better QOL & Lower pollution & No crowd in daily routine & Less traffic concerns \\
Poor QOL & Higher pollution & Heavy crowd & Excessive traffic concerns \\
\hline
\end{tabular}

\section{Discussion}

The results have demonstrated that there is a need of certain awareness programs to promote better quality of life among the adults in charity homes in Saudi Arabia. The results have identified the gaps concerning the management of the charity homes. According to CDC (2015), physical activities; such as regular exercise, are effective in enhancing bodily and mental conditions, particularly in aged people. It would prevent various cardiac conditions that are common to occur in people, aged 50 years or above. Moreover, it will assist them in keeping diabetic conditions in control. As it is generally accepted that diabetes is found among elderly people, charitable homes in Kingdom of Saudi Arabia (KSA) must institute various exercises, depending on age that will not improve their physical health, but keep them engaged in mental activity as well.

A study by Nante, et al. (2016) has conducted a study based on quality of life, which has shown that the educational qualification, length of stay, and gender were not associated with poorer health associated quality of life among refugees in Italy. Elderly refugees were observed with low scores in various dimensions of the SF-36. African refugees reported a significant $\mathrm{HRQ}$ oL than others, which might be because of different health perspectives.

Gargiulo et al. (2012) suggested that individuals with low education were observed to have adverse health issues. Similarly Pahwa et al. (2012) demonstrated that depressive symptoms are more common among the migrant women and individuals, having low educational background in Canada. Mental stress was seemed to be less common among the migrant women. Furthermore, a Swedish study represented that Iranian women had a decreased strength with a shorter time of residence (Koochek et al., 2007).

Lukas et al. (2013) investigated the approaches of pain management in the residents of nursing homes. It has been concluded that treatment approaches for the residents are suboptimal and required substantial improvement. Zaidi et al. (2012) investigated QoL in HIV-positive patients. The population of the study consisted of patients in Malaysian shelter homes, 27 research participants responded to the WHO questionnaire. The questionnaire was related to the QoL of HIV-infected people (WHOQOL-HIV BREF). Six analyzed domains included physical activity, psychological status, independence level, social relationships, environmental issues, and cultural beliefs (personal, religious, and spiritual). The participants responded positively for all six domains. The participants showed facilitated and improved living standard among the charity homes residents. Lynn et al. (2014) argued that there is insufficient information available related to self-harm in family shelters. The study also analyzed the prevalence of suicidal ideation and the effect of different risk factors.

Stated by Rubio-Tapia, et al. (2013); the celiac disease (CD) is frequently targeting adults causing diarrhea and related metabolism disturbance (Rubio-Tapia et al., 2013). It is caused mainly due to unhealthy food consumption that contains gluten. The consequent effect of CD leads to osteoporosis, miscarriage or infertility, and Type 1 diabetes and cancer at extreme.

The study recommended further improvements in charity homes related to awareness, safety, security, and medication facilities. It would result in positive health outcomes for the vulnerable population residing in these 
charity homes. In order to attain desirable results for better quality of life in charitable homes, adults should be provided with healthy diet, workout sessions, teamwork, interacting activities, etc. It will boost inner energy and manage stress levels. Moreover, it is important to provide them an interactive environment that would improve their self-esteem and self-image. These attributes are extremely vital for such adults, so they can remain functional and ambitious in life. Similarly, the present study also suggested that management of charitable homes in KSA should arrange workshops and seminars that would teach adults to deal with constantly building stress, depression, and anger. It is essential to develop some self-management skills in these people, so they prosper in their future. Moreover, enhancement of self-management skills is also important to improve environmental factors of charitable homes. An interactive surrounding with fellows in charity home will give them an opportunity to share their intrinsic and extrinsic issues and desires, providing them mental and social peace.

Management of such homes must arrange proper employment opportunities through which they can further enhance their quality of life. The management can arrange various employment seminars, training and grooming sessions based on education levels of people. Quality of living will improve as independency, and self-confidence would develop in these adults. Besides, adults in charitable homes can help in improving national standards of living by reducing dependency ratio through this channel.

\section{Acknowledgement}

The authors are very thankful to all the associated personnel in any reference that contributed in/for the purpose of this research. Furthermore, this research is not funded through any source. The authors declare no conflict of interest.

\section{Competing Interests Statement}

The authors declare that there are no competing or potential conflicts of interest.

\section{References}

Aydin, R., Unal, E., Gokler, M. E., Metintas, S., Emiral, G. O., Ozay, O., \& Isikli, B. (2016). An evaluation of home health care needs and Quality of Life among the elderly in a semi-rural area of Western Turkey. European Geriatric Medicine, 7(1), 8-12. https://doi.org/10.1016/j.eurger.2015.10.005

CDC, Division of Nutrition, Physical Activity, and Obesity. (2015). Centers for Disease Control and Prevention.

Gargiulo, L., Iannucci, L., \& Tinto, A. (2012). The Use of Health-Related Quality of Life Measures in Official Statistics: The Italian Experience. In Quality of life in Italy (pp. 291-304). Springer Netherlands. https://doi.org/10.1007/978-94-007-3898-0_15

Ha, Y., Narendorf, S. C., Santa Maria, D., \& Bezette-Flores, N. (2015). Barriers and facilitators to shelter utilization among homeless young adults. Evaluation and program planning, 53, 25-33. https://doi.org/10.1016/j.evalprogplan.2015.07.001

Koochek, A., Montazeri, A., Johansson, S. E., \& Sundquist, J. (2007). Health-related quality of life and migration: A cross-sectional study on elderly Iranians in Sweden. Health and Quality of Life Outcomes, 5(1), 60. https://doi.org/10.1186/1477-7525-5-60

Lukas, A., Mayer, B., Fialová, D., Topinkova, E., Gindin, J., Onder, G., ... \& Denkinger, M. D. (2013). Treatment of pain in European nursing homes: results from the Services and Health for Elderly in Long TERm Care (SHELTER) study. Journal of the American Medical Directors Association, 14(11), 821-831. https://doi.org/10.1016/j.jamda.2013.04.009

Lynn, C. J., Acri, M. C., Goldstein, L., Bannon, W., Beharie, N., \& McKay, M. M. (2014). Improving youth mental health through family-based prevention in family homeless shelters. Children and youth services review, 44, 243-248. https://doi.org/10.1016/j.childyouth.2014.05.024

Nante, N., Gialluca, L., De Corso, M., Troiano, G., Verzuri, A., \& Messina, G. (2016). Quality of life in refugees and asylum seekers in Italy: A pilot study. Annali dell'Istituto Superiore di Sanità, 52(3), 424-427. https://doi.org/10.4415/ANN_16_03_14

Pahwa, P., Karunanayake, C. P., McCrosky, J., \& Thorpe, L. (2012). Longitudinal trends in mental health among ethnic groups in Canada. Chronic diseases and injuries in Canada, 32(3). https://doi.org/10.1186/1471-2288-9-84

Rubio-Tapia, A., Hill, I. D., Kelly, C. P., Calderwood, A. H., \& Murray, J. A. (2013). ACG clinical guidelines: 
diagnosis and management of celiac disease. The American journal of gastroenterology, 108(5), 656-676. https://doi.org/10.1038/ajg.2013.79

Saudi Gazette. (2015). Ministry moves to restructure shelter homes after breakout. Saudi Gazette.

Veenema, T. G., Rains, A. B., Casey-Lockyer, M., Springer, J., \& Kowal, M. (2015). Quality of healthcare services provided in disaster shelters: An integrative literature review. International emergency nursing, 23(3), 225-231. https://doi.org/10.1016/j.ienj.2015.01.004

WHOQOL. (1995). Introducing the WHOQOL instruments. World Health Organization.

World Health Organization. (2014). WHOQOL-Bref: introduction, administration, scoring and generic version of the assessment. Field Trial Version. Geneva, Switzerland: WHO, 1996.

Zaidi, W. A. A. W., Jamalut, Y., Nor, B. M., Zulkapli, F. H., \& Hanapiah, F. A. (2012). Quality of life amongst HIV positive patients in Malaysian HIV shelter homes. Procedia-Social and Behavioral Sciences, 35, 213-220. https://doi.org/10.1016/j.sbspro.2012.02.081

\section{Copyrights}

Copyright for this article is retained by the author(s), with first publication rights granted to the journal.

This is an open-access article distributed under the terms and conditions of the Creative Commons Attribution license (http://creativecommons.org/licenses/by/4.0/). 